\title{
Interaction between Hymenoscyphus fraxineus and Phytophthora species on young Fraxinus excelsior seedlings
}

\author{
by Ivan Milenkovići ${ }^{1,2}$, Nenad Keča ${ }^{3}$, Dragan Karadžíc ${ }^{3}$, Justyna A. Nowakowska4 \\ Tomasz Oszako ${ }^{5}$, Katarzyna Sikora ${ }^{5}$ and Miłosz Tkaczyk ${ }^{5}$
}

\begin{abstract}
Common pathogenicity tests on 16-month-old ash plants were performed using isolates of Hymenoscyphus fraxineus and three different Phytophthora spp. isolated under declining ash trees in Wolica Nature reserve in Poland. There were no statistically significant differences among the different inoculation treatments and lesion lengths averaged $1.67 \mathrm{~cm}$. After analyses of inoculated roots, five out of 10 root parameters showed statistically significant differences, and after a Duncan's Multiple Range test, significant differences were found with control plants while there were no differences among the treatments. The largest root loss was with the treatment inoculated with both $H$. fraxineus and P. plurivora (HF + PP), and both fine and total root lengths were 2.30 and 2.27 times smaller, respectively, than the non-inoculated control. The earliest mortality of young ash plants was observed also with the HF + PP treatment. Results showed high aggressiveness of $H$. fraxineus to young ash plants, with indications that root infections with Phytophthora spp. may contribute to greater damage, but more research is needed to clarify the interaction between H. fraxineus and Phytophthora spp. in ash dieback.
\end{abstract}

Key words: Hymenoscyphus fraxineus (Chalara fraxinea), ash dieback, root pathogens, pathogenicity, Phytophthora species

\section{RÉSUMÉ}

On a effectué des tests de pathogénicité combinée sur des plants âgés de 16 mois avec deux isolats d'Hymenoscyphus fraxineus et trois différentes espèces de Phytophthora spp isolées sous des frênes dépérissants dans la réserve naturelle de Wolica en Pologne. Il n'y a pas eu de différence significative entre les différents traitements d'inoculation et les lésions mesuraient en moyenne 1,67 cm. Lanalyse des racines inoculées a révélé que cinq des 10 paramètres des racines montraient des différences significatives et un test de Duncan a permis de confirmer qu'il y avait aussi des différences significatives avec les plants témoins, bien qu'il n'y ait pas eu de différence entre les traitements. La perte de racines la plus importante a été enregistrée dans le traitement inoculé avec une combinaison de $H$. fraxineus et $P$. plurivora $(\mathrm{HF}+\mathrm{PP})$; les racines fines et grossières se sont avérées 2,30 et 2,27 fois plus courtes respectivement que celles des plants témoins sans inoculation. Les jeunes plants de frêne sont aussi morts plus hâtivement lorsqu'ils avaient reçu le traitement (HF + PP). Les résultats ont montré la grande agressivité de $H$. fraxineus pour les jeunes plants de frêne, indiquant de plus qu'une infection racinaire par Phytophthora spp. pouvait en accroitre le dommage. Il faudra poursuivre les recherches pour mieux comprendre comment $H$. fraxineus et Phytophthora spp. interagissent dans le dépérissement du frêne.

Mots-clés: Hymenoscyphus fraxineus (Chalara fraxinea), dépérissement du frêne, agents pathogènes des racines. pathogénicité, espèces de Phytophthora

\section{Introduction}

European ash (Fraxinus excelsior L.) dieback is a major problem affecting plantations and natural ash stands in most European countries (Husson et al. 2012; Rytkönen et al. 2011). The first symptoms of this phenomenon were observed in the early 1990s in north-eastern Poland and Lithuania (Kowalski 2006; Timmermann et al. 2011), and a new species, Chalara fraxinea Kowalski (Kowalski 2006), as the cause of mass mortality of ash trees (Kowalski and Holdenrieder 2009a, 2009b). Kowalski and Holdenrieder (2009b) also suggested Hymenoscyphus albidus (Gillet) W. Phillips as a teleomorph of C. fraxinea, while Queloz et al. (2011) described $H$. pseudoalbidus Queloz as closely related but dif- ferent from $H$. albidus. Finally, Baral et al. (2014) suggested Hymenoscyphus fraxineus (Kowalski) Baral, Queloz and Hosoya as a proper scientific name for this pathogenic fungus. Based on the available literature, the most recent countries where $H$. fraxineus has been reported on European ash were Serbia (Keča et al. 2017) and Montenegro (Milenković et al. 2017). Narrow-leaved ash (Fraxinus angustifolia Vahl.) is also susceptible to $H$. fraxineus after European ash (Kirisits et al. 2010).

The presence of pathogens from the genus Phytophthora under declining ash trees has been connected with the dieback. Several studies during the last two decades reported the occurrence of these pathogenic organisms in rhizosphere

\footnotetext{
${ }^{1}$ Institute of Forestry Belgrade, Kneza Višeslava 3, 11030 Belgrade, Serbia; ivan.milenkovic@sfb.bg.ac.rs

${ }^{2}$ Phytophthora Research Centre, Mendel University, Zemědělská 1, 61300 Brno, Czech Republic

${ }^{3}$ University of Belgrade-Faculty of Forestry, Kneza Višeslava 1, 11030 Belgrade, Serbia

${ }^{4}$ Cardinal Stefan Wyszynski University in Warsaw, Faculty of Biology and Environmental Sciences, Wóycickiego 1/3 Street, 01-938

Warsaw, Poland

${ }^{5}$ Forest Protection Department, Forest Research Institute-IBL, Braci Leśnej 3, 05-090 Raszyn, Poland
} 
soils and necrotic tissues associated with severe damage of significant forest tree species (Brasier et al. 2005; Jung et al. 2013), including ash (Orlikowski et al. 2011; Akilli et al. 2013). Tkaczyk et al. (2016) also reported isolation of several different Phytophthora species from ash in Białowieża Forest Nature Reserve in Poland. Nevertheless, our understanding of Phytophthora species associated with ash is still very limited, as is information on the interaction between these two pathogenic organisms in the ash dieback phenomenon.

During the studies of ash dieback in the Wolica Nature Reserve, three different Phytophthora species were isolated from rhizosphere soil of declining ash trees, including $P$. megasperma Drechsler, $P$. plurivora Jung \& Burgess, and $P$. sp. hungarica Bakonyi et al. (Pacia et al. 2017). In addition, high disease severity and different $H$. fraxineus symptoms were recorded. Due to lack of the data about the interaction of $H$. fraxineus and Phytophthora species on ash, a pathogenicity test of 16-month-old Fraxinus excelsior seedlings with $H$. fraxineus and Phytophthora species was performed to: i) test whether root loss caused by the activity of Phytophthora species influenced the extent of necrosis caused by $H$. fraxineus; ii) to test whether the infections with $H$. fraxineus influenced root loss caused by Phytophthora species; and, ii) to clarify the possible interaction of $H$. fraxineus and Phytophthora species.

\section{Materials and Methods}

Sampling, isolation, and identification of Hymenoscyphus fraxineus

Sampling and isolation of $H$. fraxineus were carried out according to Kowalski (2006). Samples were collected from symptomatic parts of the stems, branches and shoots in Wolica Nature Reserve (Forest District Chojnów (RDLP) in Warsaw, Poland; coordinates: $51.1^{\circ} \mathrm{N}, 10.5^{\circ} \mathrm{E}$ ). Samples 3-4 $\mathrm{mm}$ were taken from the transition zone between necrotic and healthy phloem tissues using a flamed scalpel. Tissue surface sterilization was performed in $1 \%$ sodium hypochlorite, with $4 \%$ active hypochlorite for three minutes. The samples were then washed three times in distilled water and plated on $18 \mathrm{~g} \mathrm{l}^{-1}$ of Malt Extract medium (MEA, Germany) and $18 \mathrm{~g} \mathrm{l}^{-}$ ${ }^{1}$ of agar (BTL, Poland). Incubation was at $18-20^{\circ} \mathrm{C}$ in the dark. After the appearance of the first hyphae, the samples were transferred onto fresh MEA medium and incubated at $20^{\circ} \mathrm{C}$ in the dark.

Four-week-old cultures were observed under a light microscope (ZEISS Axioskop 2) equipped with a Nikon Dsfil camera and NIS Elements AR4 $4^{\circ}$ software. The identification of isolates as Hymenoscyphus fraxineus was based on disease symptoms, on the colony shape of pure cultures incubated for four weeks in the dark at $20^{\circ} \mathrm{C}$, and on the shape and size of phialides observed in the pure cultures and compared with previously identified isolates.

\section{Isolates of Phytophthora species used in the experiment}

Isolates were taken from the Forest Research Institute-IBL collection of isolates, all originating from declining ash stands in Wolica Nature Reserve and previously morphologically and molecularly identified. Three different Phytophthora species included isolate IBL/2012/8/1 of $P$. plurivora (JX274424), IBL/2012/9/3 of P. megasperma (JX274423), and IBL/2012/9/8 of $P$. sp. hungarica (JX274428).

\section{Plant preparation and experiment design}

Fraxinus excelsior seedlings 16-months-old were planted in individual $1 \mathrm{~L}$ pots containing $1 \mathrm{~L}$ of non-infected, autoclaved substrate mixture of perlite (Agra perlite ${ }^{\bowtie}$, RHP, Netherlands), humus (Agrohum, Lomianki, Poland) and sand, in volume proportion 1:1:1. In addition, to avoid excessive root disturbance and wounding at the time of inoculation, two sterile $15-\mathrm{ml}$ glass tubes were placed in each pot to a depth of $15 \mathrm{~cm}$ at $5-\mathrm{cm}$ from the stem base to provide a cavity for inoculation.

Five different combinations of pathogenicity treatments with $H$. fraxineus and Phytophthora spp. were included and 10 plants per combination were used; the controls were the sixth treatment (Table 1). Since $P$. plurivora was most often isolated under ash trees in the study area, one combination included an inoculum of only $P$. plurivora while the second included a mixture of all the isolated species, $P$. plurivora $+P$. megasperma $+P$. sp. hungarica in inoculum proportions of 1:1:1. The temperature in the greenhouse ranged between 22 ${ }^{\circ} \mathrm{C}$ and $25^{\circ} \mathrm{C}$ and the day length was set at $14 \mathrm{hr}$ using an artificial light system.

\section{Pathogenicity tests with Phytophthora species}

Pathogenicity tests were done using the soil infestation test according to Jung et al. (1996), and the inoculum consisted of 4- to 6-week-old cultures of individual isolates of Phytophthora spp. grown at $20^{\circ} \mathrm{C}$ in $500 \mathrm{ml}$ Erlenmeyer flasks on an autoclaved mixture of $250 \mathrm{~cm}^{3}$ of fine vermiculite (Agra vermiculite ${ }^{\circledast}$ RHP, Netherlands) and $20 \mathrm{~cm}^{3}$ of whole millet seeds thoroughly moistened with $175 \mathrm{ml}$ of vegetable juice broth (200 $\mathrm{ml} \mathrm{1}^{-1}$ of vegetable juice (Tymbark, Poland), $800 \mathrm{ml} \mathrm{1}^{-1}$ distilled water amended with $\left.3 \mathrm{~g}^{-1} \mathrm{CaCO}_{3}\right)$. Plants were placed into $80 \mathrm{~L}$ boxes (10 pots in each) and glass tubes

Table 1. Size of the plants and necrotic lesion lengths (mean and standard error] a month after ash shoots were inoculated with Hymenoscyphus fraxineus and four months after Phytophthora inoculation

\begin{tabular}{lccc}
\hline Treatments & $\begin{array}{c}\text { Height } \\
(\mathbf{c m})\end{array}$ & $\begin{array}{c}\text { Collar } \\
\text { diameter } \\
(\mathbf{m m})\end{array}$ & $\begin{array}{c}\text { Lesion } \\
\text { length } \\
(\mathbf{m m})\end{array}$ \\
\hline Control & $15.2 \pm 4.3$ & $4.5 \pm 0.8$ & 0.00 \\
H. fraxineus & $14.3 \pm 3.4$ & $4.5 \pm 0.8$ & $1.7 \pm 0.4^{2}$ \\
H. fraxineus + Mix 1 & $14.6 \pm 3$ & $4.5 \pm 1$ & $1.6 \pm 0.3^{2}$ \\
H. fraxineus + P. plurivora & $15.7 \pm 3.6$ & $4.4 \pm 0.7$ & $1.7 \pm 0.4^{3}$ \\
Mix & $14.6 \pm 1.3$ & $3.3 \pm 0.3$ & 0.00 \\
P. plurivora & $17.7 \pm 1.3$ & $4 \pm 0.3$ & 0.00 \\
\hline
\end{tabular}

${ }^{1}$ Mix of Phytophthora species included P. plurivora + P. megasperma $+P$. sp. hungar ica in inoculum volume proportion 1:1:1;

${ }^{2}$ Dieback of one plant a month after ash shoots were inoculated

${ }^{3}$ Dieback of three plants a month after ash shoots were inoculated. 
removed. Prior to inoculation, the inoculum was rinsed under distilled water. Cavities were filled with inoculum at a ratio of 20 to $25 \mathrm{~cm}^{3}$ of inoculum per $1000 \mathrm{~cm}^{3}$ of the soil mixture. Controls were inoculated only with rinsed, sterile vermiculite-vegetable juice mixture at the same ratio. Each box was flooded immediately after inoculation for $72 \mathrm{hr}$ and flooding repeated once every three weeks for $72 \mathrm{hr}$. During the second and every other flooding, re-isolations from the infested substrates were made by the leaf baiting method using young beech and oak leaves to determine the ability of the isolates to spread, survive and form sporangia with zoospores in the soil. After every flooding, discarded water was sterilized with sodium hypochlorite.

\section{Pathogenicity test with $\mathrm{H}$. fraxineus}

Inoculum for $H$. fraxineus infections was prepared by transferring pure cultures of the pathogen onto MEA medium and growing for 3-4 weeks at $20^{\circ} \mathrm{C}$ in the dark. Young shoots of healthy ash trees were collected and strips $2-\mathrm{mm}$ wide were cut tangentially into 4-5 $\mathrm{mm}$ long pieces, placed on to Petri plates and sterilized. The sterilized pieces were plated on the surface of pure cultures and left to be overgrown by $H$. fraxineus mycelium for four weeks.

Inoculation of ash with $H$. fraxineus followed Bakys et al. (2009) and Kowalski and Holdenrieder (2009a). The bark of young stems was cleaned and surface sterilized with cotton moistened in 70\% ethanol. At 5-7 cm above the soil level, 4-5 $\mathrm{mm}$ pieces of bark were removed with a flamed sterile scalpel. Prepared pieces of inoculum were placed onto the wounded tissue and sealed with Parafilm "M" (Bemis, USA) and aluminum foil. The control group was inoculated with sterile pieces of autoclaved wood. Inoculation with $H$. fraxineus was performed three months after the inoculations with Phytophthora species.

\section{Re-isolation and examination}

Four months after inoculation with Phytophthora species and a month after inoculation with $H$. fraxineus, plants were removed from the substrate and roots washed under running water. After washing, re-isolations were done by plating necrotic parts and pieces of fine roots onto selective agar media (V8-PARPNH) (Jung et al. 1996). Pieces of fine roots from control groups, as well as from the group inoculated only with $H$. fraxineus, were also plated onto selective agar media.

All roots were scanned using WinRhizo ${ }^{\varpi}$ software (Regent Instruments, Canada), and EPSON Perfection V700 Photo Scanner. Roots scanned with WinRhizo software were dried at $65{ }^{\circ} \mathrm{C}$ in a drying oven until constant weight (Termaks Series 2000, Norway), and dry biomass was measured of fine and coarse roots using the Sartorius analytic A200S scale (GMBH, Germany).

Sealed plants, inoculated with $H$. fraxineus were opened and analyzed for the presence of any necrosis and after measurement of necrotic lengths in the axial direction above the inoculation points, bark tissues were surface sterilized and reisolations were attempted from necrotic edges by placing small necrotic pieces onto MEA amended with streptomycin. Pieces from the control group were also plated.

\section{Statistical analyses}

Lesion lengths as well as measurements of root parameters were tested using one-way analyses of variance at $p=0.05$. Differences between mean necrotic length were analyzed using the Kruskal-Wallis test while differences between the other root parameter means were examined with the Duncan's Multiple Range post hoc test $(\alpha=0.05)$. All the analyses were performed with STATISTICA ${ }^{\circ}$ (ver. 12).

\section{Results \\ Hymenoscyphus fraxineus necrotic lesion lengths}

Four months after inoculation with Phytophthora species and a month after inoculation with $H$. fraxineus, the first plants inoculated with $H$. fraxineus started to decline and the field experiment was ended. Re-isolations were successful in $83 \%$ of attempted cases. Lesion lengths ranged from 0.9 to $2.4 \mathrm{~cm}$, with a mean value of $1.7 \mathrm{~cm}$ for all plants (Table 1). The results show that these treatments did not differ: $H$. fraxineus, $H$. fraxineus + Mix, and $H$. fraxineus $+P$. plurivora $(\mathrm{p}<0.97)$ in necrotic lesion lengths. However, these treatments were different from the controls and other treatments based on standard error. The results also show that different treatments did not influence the necrosis length.

\section{Results of soil infestation test}

Re-isolations were successful in $100 \%$ of plated necrotic parts, and in $87.5 \%$ of plated root pieces. Root pieces from controls and treatment with only $H$. fraxineus inoculation were negative after the re-isolations. For specific fine root length, specific root tip density, fine root length per main root length, number of fine root tips per main root length and fine root length per dry weight of main root, there were no statistically significant differences. For tests where significantly significant treatment differences were found by ANOVA $(p<0.05)$, then Duncan's Multiple Range test was performed (Table 2).

In the cases where there were significant treatment effects, the non-inoculated control differed significantly from the remaining treatments. As well, the lowest values in general in terms of area, weight or length was after inoculation with both $H$. fraxineus and $P$. plurivora, but this was significantly different only from the non-inoculated control (Table 2). In the case of main root length, there was no statistically significant difference between the non-inoculated control and the treatments with inoculation using a mix of Phytophthora species or the single $P$. plurivora (Table 2). In the remaining cases, a significant difference was found only in comparison to the non-inoculated control with no statistically significant difference among the treatments.

\section{Discussion}

The results show the ability of Phytophthora spp. and Hymenoscyphus fraxineus to infect root systems of young ash seedlings and to cause damage and different root losses. However, there were generally no significant differences between root inoculation with Phytophthora spp. on lengths of necrotic lesions caused by $H$. fraxineus. Moreover, significant root losses were recorded compared to the non-inoculated, but not among treatments including different combinations of Phytophthora spp., H. fraxineus, and with both Phytoph- 
Table 2. Mean values and the results of Duncan's test for five root parameters of common ash after the pathogenicity soil infestation test

\begin{tabular}{lccccccc}
\hline & \multicolumn{3}{c}{ Treatments } \\
\cline { 2 - 7 } Parameter & Control & $\begin{array}{c}\text { H. fraxineus } \\
+ \text { Mix }\end{array}$ & $\begin{array}{c}\text { H. fraxineus } \\
+ \text { P. plurivora }\end{array}$ & H. fraxineus & Mix & P. plurivora & (p) \\
\hline Total root length $(\mathrm{cm})$ & $768 \mathrm{a}$ & $415 \mathrm{~b}$ & $337 \mathrm{~b}$ & $523 \mathrm{~b}$ & $417 \mathrm{~b}$ & $416 \mathrm{~b}$ & 0.005 \\
Fine root length $(\mathrm{cm})$ & $755 \mathrm{a}$ & $406 \mathrm{~b}$ & $328 \mathrm{~b}$ & $513 \mathrm{~b}$ & $408 \mathrm{~b}$ & $403 \mathrm{~b}$ & 0.006 \\
Mother root length $(\mathrm{cm})$ & $13 \mathrm{a}$ & $8.7 \mathrm{~b}$ & $8.8 \mathrm{~b}$ & $9.3 \mathrm{~b}$ & $9 \mathrm{~b}$ & $13 \mathrm{a}$ & 0.019 \\
Number of Tips (n) & $1426 \mathrm{a}$ & $590 \mathrm{~b}$ & $439 \mathrm{~b}$ & $624 \mathrm{~b}$ & $508 \mathrm{~b}$ & $585 \mathrm{~b}$ & 0.001 \\
Fine Root Surface Area $\left(\mathrm{cm}^{2}\right)$ & $131 \mathrm{a}$ & $74 \mathrm{~b}$ & $61 \mathrm{~b}$ & $81 \mathrm{~b}$ & $72 \mathrm{~b}$ & $66 \mathrm{~b}$ & 0.002 \\
\hline
\end{tabular}

thora and $H$. fraxineus. Out of 10 root parameters, five had significant effects and means were separated with Duncan's Multiple Range test. The lowest value of fine root length, as one of the most important parameters reflecting root condition, was recorded in the case of dual inoculation with $P$. plurivora and $H$. fraxineus. This value was 2.3 times smaller and statistically significantly different only with the non-inoculated control, while total root length was 2.3 times smaller than the non-inoculated control. Compared to the $H$. fraxineus treatment, fine root lengths and mother root lengths were 1.6 times smaller but not statistically significant. The decline of the first three ash plants was recorded in this treatment which suggests that mortality was driven by root infection after infection of the shoot tissue. However, further largescale field and pathogenicity studies are required to support this conclusion. Similar trends were found with other root parameters, but they were not statistically significantly different from other treatments including the non-inoculated control.

The results in this study are in agreement with previous studies on the high aggressiveness of $H$. fraxineus (e.g., Kowalski 2006; Kowalski and Holdenrieder 2009a, 2009b). Ash dieback is a serious problem affecting most European countries and one of the main goals in management strategies is to determine all the contributing factors of ash dieback in Europe. In addition to infections by $H$. fraxineus as a main cause of ash dieback, other factors may possibly play role in this phenomenon, including infection with Phytophthora species (Orlikowski et al. 2011; Akilli et al. 2013) and Armillaria species (Skovsgaard et al. 2010; Enderle et al. 2013). Results showed high aggressiveness of $H$. fraxineus to young ash plants, with indications that root infections with Phytophthora spp. may contribute to greater damage, but more research is needed to clarify the interaction between $H$. fraxineus and Phytophthora spp. in ash dieback.

\section{Acknowledgements}

We thank FRAXBACK COST Action FP1003, for giving the STSM to Ivan Milenković. We are also grateful to the project TR37008 financed by the Ministry of Education, Science and Technological Development, the Republic of Serbia, and IBL grant 240325 for material support during this work, and to IBL Grant for the Scholarship to Ivan Milenković. We are also very grateful to Mr. Artur Pacia and Malgorzata Borys for help in the laboratory work.

\section{References}

Akilli, S., Ç. Ulubaș Serçe, Y.Z. Katircioğlu and S. Maden. 2013. Phytophthora dieback on narrow leaved ash in the Black Sea region of Turkey. Forest Pathol. 43: 252-256. doi:10.1111/efp.12024.

Bakys, R., R. Vasaitis, P. Barklundm, K. Ihrmark and J. Stenlid. 2009. Investigations concerning the role of Chalara fraxinea in declining Fraxinus excelsior. Plant Pathol. 58: 284-292. doi:10.1111/ j.1365-3059.2008.01977.x.

Baral, H.O., V. Queloz and T. Hosoya. 2014. Hymenoscyphus fraxineus, the correct scientific name for the fungus causing ash dieback in Europe. IMA Fungus 5(1): 79-80. doi:10.5598/imafungus. 2014.05.01.09.

Brasier, C.M., P.A. Beales, S.A. Kirk, S. Denman and J. Rose. 2005. Phytophthora kernoviae sp. nov., an invasive pathogen causing bleeding stem lesions on forest trees and foliar necrosis of ornamentals in the UK. Mycol. Res. 109(8): 853-859. Available from: http:// dx.doi.org/10.1017/S0953756205003357 [accessed 21 August 2017]. Enderle, R., F. Peters, A. Nakou and B. Metzler. 2013. Temporal development of ash dieback symptoms and spatial distribution of collar rots in a provenance trial of Fraxinus excelsior. Eur. J. For. Res. 132: 865-876. https://doi.org/10.1007/s10342-013-0717-y.

Husson, C., O. Caël, J.P. Grandjean, L.M. Nageleisen and B. Marçais. 2012. Occurrence of Hymenoscyphus pseudoalbidus on infected ash logs. Plant Pathol. 61: 889-895. doi:10.1111/j.13653059.2011.02578.x.

Jung, T., H. Blaschke and P. Neumann. 1996. Isolation, identification and pathogenicity of Phytophthora species from declining oak stands. Eur. J. of For. Pathol. 26: 253-272. doi:10.1111/j.1439-0329. 1996.tb00846.x.

Jung, T., A.M. Vettraino, T. Cech and A. Vannini. 2013. The impact of invasive Phytophthora species on European forests. In: Lamour K. (ed.) Phytophthora a global perspective. pp. 146-158. CABI, Plant protection series 2.

Keča, N., T. Kirisits and A. Menkis. 2017. First Report of the Invasive Ash Dieback Pathogen Hymenoscyphus fraxineus on Fraxinus excelsior and F. angustifolia in Serbia. Baltic Forest. 23(1): 56-59. Available from https://www.balticforestry.mi.lt/bf/PDF_Articles/ 2017-23\%5B1\%5D/Baltic\%20Forestry\%202017.1_056-059.pdf [accessed 09 August 2017].

Kirisits, T., M. Matlakova, S. Mottinger-Kroupa, E. Halmschlager and F. Lakatos. 2010. Chalara fraxinea associated with dieback of narrow-leafed ash (Fraxinus angustifolia). Plant Pathol. 59: 411. doi:10.1111/j.1365-3059.2009.02162.x.

Kowalski, T. 2006. Chalara fraxinea sp. nov. associated with dieback of ash (Fraxinus excelsior) in Poland. Forest Pathol. 36: 264-270. doi:10.1111/j.1439-0329.2006.00453.x.

Kowalski, T. and O. Holdenrieder. 2009a. Pathogenicity of Chalara fraxinea. Forest Pathol. 39: 1-7. doi:10.1111/j.1439-0329.2008.00565.x. 
Kowalski, T. and O. Holdenrieder. 2009b. The teleomorph of Chalara fraxinea, the causal agent of ash dieback. Forest Pathol. 39: 304-308. doi:10.1111/j.1439-0329.2008.00589.x.

Milenković, I., T. Jung, Z. Stanivuković and D. Karadžić. 2017. First report of Hymenoscyphus fraxineus on Fraxinus excelsior in Montenegro. Forest Pathol. doi: 10.1111/efp.12359.

Orlikowski, L.B., M. Ptaszek, A. Rodziewicz, J. Nechwatal, K. Thinggaard and T. Jung. 2011. Phytophthora root and collar rot of mature Fraxinus excelsior in forest stands in Poland and Denmark. Forest Pathol. 41: 510-519. doi:10.1111/j.1439-0329.2011.00714.x.

Pacia, A. et al. 2017. Common Ash Stand Affected by Ash Dieback in the Wolica Nature Reserve in Poland. Baltic Forest. 23(1): 183-197. Available from: https://www.balticforestry.mi.lt/bf/PDF Articles/2017-23\%5B1\%5D/Baltic\%20Forestry\%202017.1_183197.pdf [accessed 19 August 2017].

Queloz, V., C.R. Grünig, R. Berndt, T. Kowalski, T.N. Sieber and O. Holdenrieder. 2011. Cryptic speciation in Hymenoscyphus albidus. Forest Pathol. 41: 133-142. doi: 10.1111/j.1439-0329. 2010.00645.x.
Rytkönen, A., A. Lilja, R. Drenkhan, T. Gaitnieks and J. Hantula. 2011. First record of Chalara fraxinea in Finland and genetic variation among isolates sampled from Åland, mainland Finland, Estonia and Latvia. Forest Pathol. 41(3): 169-174. doi:10.1111/j.14390329.2010.00647.x.

Skovsgaard, J.P., I.M. Thomsen, I.M. Skovgaard and T. Martinussen. 2010. Associations among symptoms of dieback in evenaged stands of ash (Fraxinus excelsior L.). Forest Pathol. 40: 7-18. doi:10.1111/j.1439-0329.2009.00599.x.

Timmermann, V., I. Børja, A.M. Hietala, T. Kirisits and H. Solheim. 2011. Ash dieback: Pathogen spread and diurnal patterns of ascospore dispersal, with special emphasis on Norway. EPPO Bull. 41: 14-20. doi:10.1111/j.1365-2338.2010.02429.x.

Tkaczyk, M., J.A. Nowakowska and T. Oszako. 2016. Phytophthora species isolated from ash stands in Białowieża Forest nature reserve. Forest Path. 46: 660-662. doi:10.1111/efp.12295.

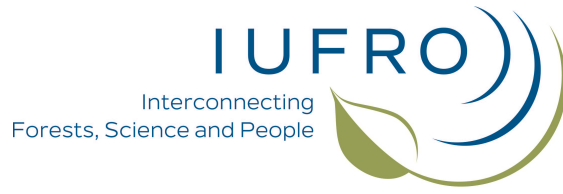

This paper is based on material that was presented at the meeting of IUFRO Working Party 7.02.02 - Foliage, Shoot and Stem Diseases, May 7-11, 2017, Niagara Falls, Ontario, Canada 